3. Kubota K. Matsuzawa T, Fujiwara T, Ito M, Hatazawa J. Ishiwata $\mathrm{K}$, Iwata R, Ido T Differential diagnosis of lung tumor with positron emission tomography: a prospective study. J Nucl Med. 1990;31:1927-32.

4. Kubota K, Yamada K, Yoshioka S, Yamada S, Ito M, Ido T. Differential diagnosis of idiopathic fibrosis from malignant lymphadenopathy with PET and F-18 fluorodexyglucose. Clin Nucl Med. 1992;17:361-3.

5. Landis K. Griffeth. Use of PET/CT scanning in cancer patients: technical and practical considerations. BUMC proceedings. 2005; 18:321-30

6. Haberkorn U. Strauss LG, Dimitrakopoulou A. Engenhart R. Oberdorfer F. Ostertag H, et al. PET studies of fluorodeoxyglucose metabolism in patients with recurrent colorectal tumors receiving radiotherapy. J Nucl Med. 1991;32:1485-90.

7. Graham MM, Peterson LM, Hayward RM: Comparison of simplified quantitative analyses of FDG uptake. Nucl Med Biol. 2000;27:647-55

8. SugawaraY, Zasadny KR, Neuhoff AW, et al. Reevaluation of the standardized uptake value for FDG. Variations with body weight and methods for correction. Radiology. 1999;213:521-5.

\section{Synchronous adenocarcinoma of the gall bladder and pancreas in a young}

\section{woman}

\section{Introduction}

Synchronous cancer of the upper gastrointestinal and biliary tract is rare, but is being increasingly detected due to newer advanced diagnostic techniques. Synchronous or metachronous cancers in the biliary system are often attributed to an abnormal pancreaticobiliary junction (APBJ), as a result of persistent reflux of pancreatic juice with subsequent biliary inflammation. ${ }^{1-4}$ However, it is very rare for gallbladder and pancreatic neoplasms to co-exist; in fact, only three previous reports mention this association..$^{5-7}$ We report a case of a young woman with synchronous cancers in the gallbladder and pancreas.

\section{Case Report}

A 35-year-old woman from rural north India presented with a six-week history of painless progressive jaundice, pruritis, vomiting, and, a right-sided abdominal lump. On examination, the patient was moderately nourished, and deeply icteric. Abdominal examination revealed hepatomegaly and a palpable distended gallbladder. The serum bilirubin was $15.6 \mathrm{mg} / \mathrm{dL}$, and serum alkaline phosphatase was 1526 IU/L [normal reference range: 0-300 IU/L). Other blood investigations including prothrombin time were normal. Ultrasound abdomen revealed an enlarged liver with normal echotexture and dilated extra- and intra-hepatic biliary radicals (IHBR). The gallbladder was distended and thick-walled, with an echo-free lumen. The pancreatic head was bulky and heteroechoic with suspicion of a mass lesion. CT scan showed a large mass (largest diameter $5 \mathrm{~cm}$ ) arising from the pancreatic head compressing the duodenum and stomach, with clear fat planes around it. The liver was enlarged, homogenous with multiple dilated intrahepatic biliary radicals (IHBR). The gallbladder was distended, with asymmetrical thickening of the wall, suspicious of malignancy. A moderate amount of free fluid was present (Figure 1). Upper GI endoscopy (side-viewing) showed a narrowed D2 lumen with extrinsic compression. There was no growth protruding from the ampulla. The mucosa around the ampulla was friable and coarse, and was biopsied. The histopathological examination revealed unremarkable duodenal mucosa with a few nests of malignant cells in the lower layers (Figure 2). With a probable diagnosis of synchronous gallbladder and pancreatic carcinoma with duodenal obstruction, exploratory laparotomy was planned. At laparotomy, we found a distended, hard, thick-walled gallbladder densely adherent to the porta and the common hepatic duct (CHD). There was also a large mass in the pancreatic head fixed to the retroperitoneum, with multiple enlarged peripancreatic lymph nodes. Two liters of free fluid was present in the peritoneal cavity. Due to the unresectable nature of the lesion, we performed a cholecystectomy, Roux-

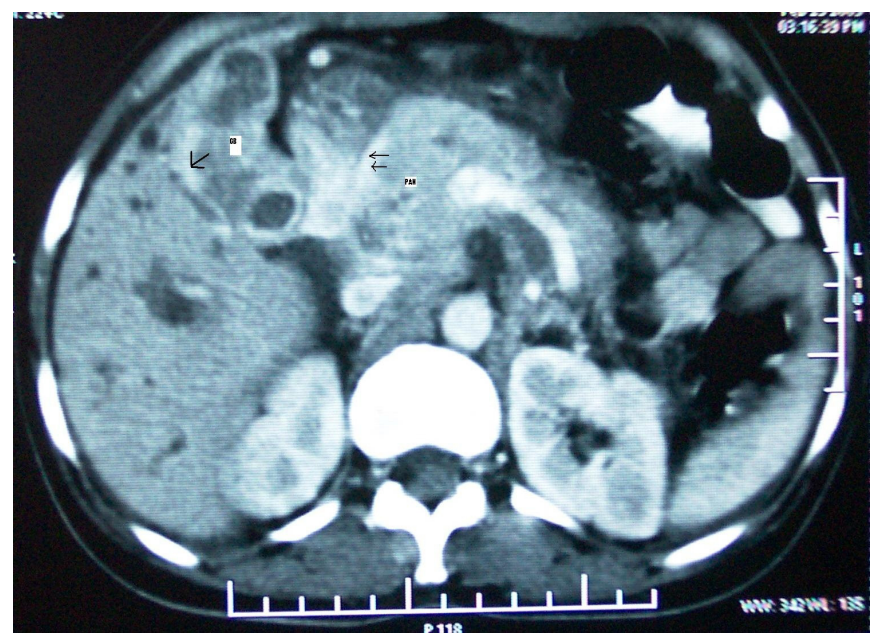

Figure 1: CT scan showing a large pancreatic mass (PAN) compressing the medial duodenal wall (double arrows). The gallbladder (GB) is also asymmetrically thickened (arrow) 
en-Y segment III hepaticojejunostomy (as the porta was frozen), and, biopsy from the pancreatic head and lymph nodes. In the postoperative period, the patient developed a leak from the bilioenteric anastomosis on the $10^{\text {th }}$ day. The subsequent clinical course was poor, with gradual deterioration of renal and pulmonary functions. The patient died 25 days after the operation. Histopathological examination revealed welldifferentiated adenocarcinoma of the gallbladder (Figure 3), and, moderately differentiated adenocarcinoma of the pancreas with predominantly solid component (Figure 4) with metastases of the latter to the lymph nodes. A final diagnosis of synchronous adenocarcinoma of the gallbladder and pancreas was made.

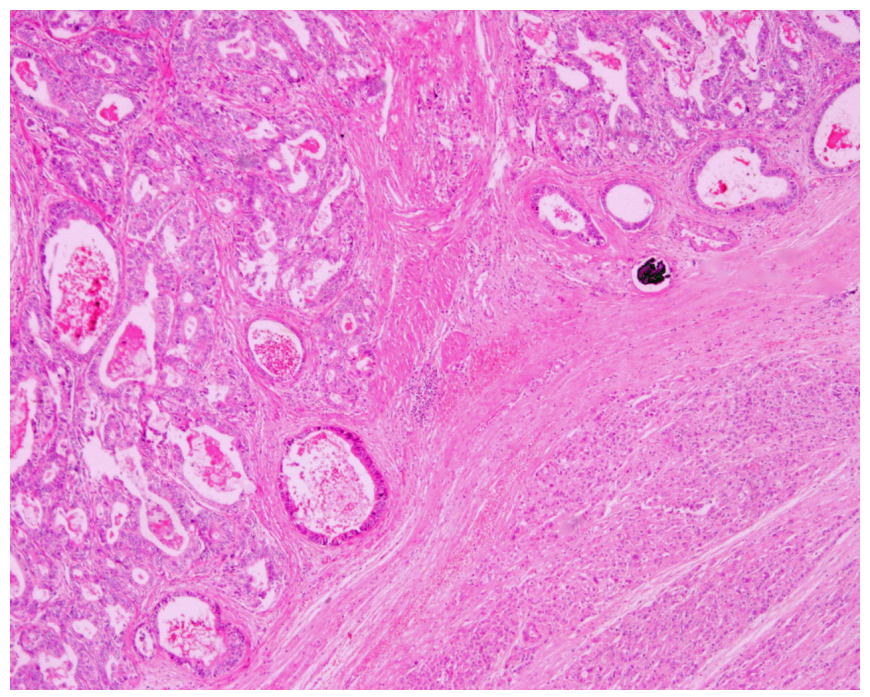

Figure 2: Section from duodenal biopsy showing unremarkable overlying mucosa with a few nests of malignant tumor cells in the submucosa (inset). H\&E x40

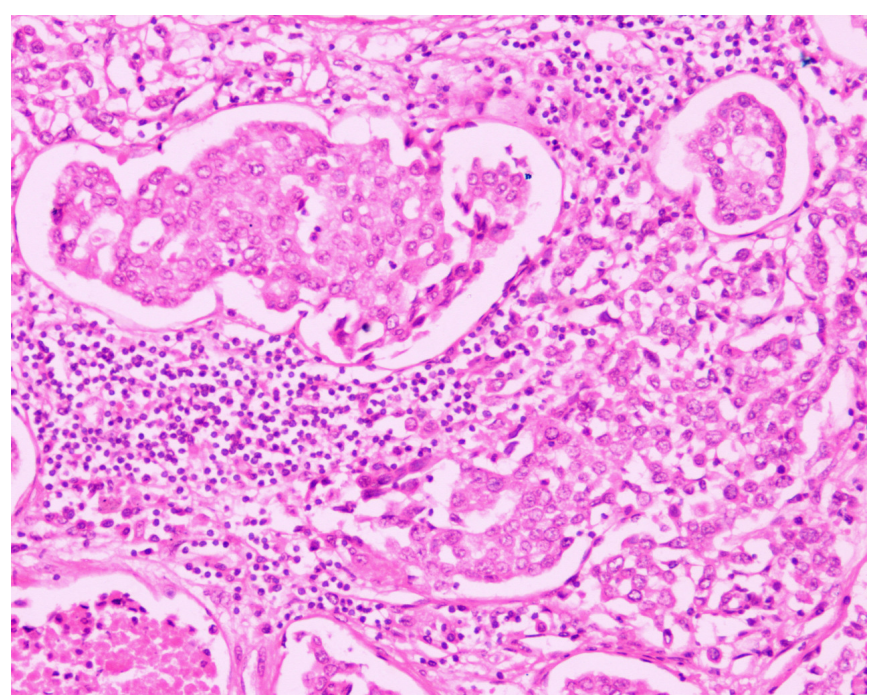

Figure 3: Section from gall bladder showing well-differentiated adenocarcinoma infiltrating into the muscularis propria. $\mathrm{H} \& \mathrm{E} x 40$

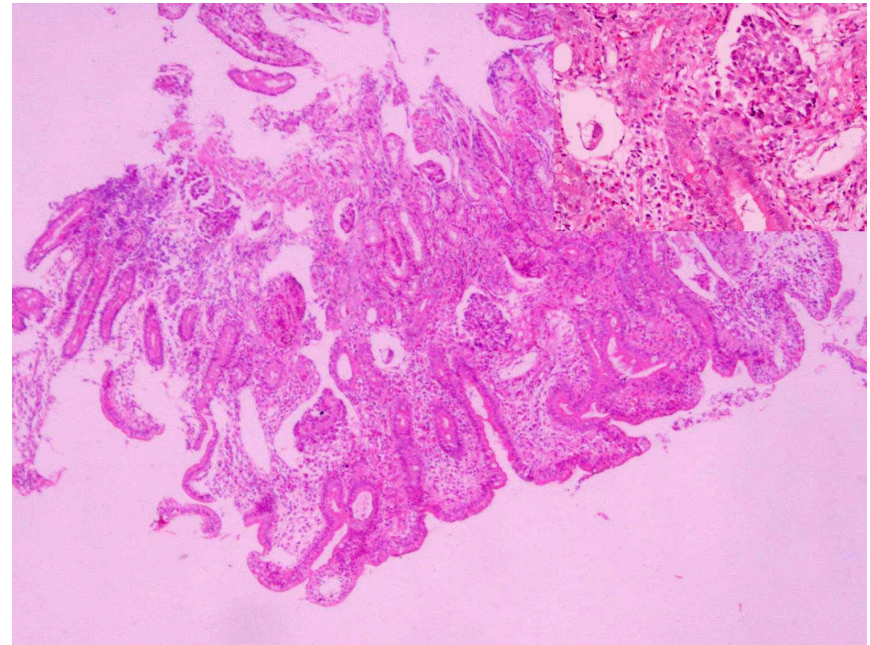

Figure 4: Section from pancreatic tumor showing mainly solid carcinoma with some gland-like differentiation and lymphatic permeation. H\&E x200

\section{Discussion}

The simultaneous occurrence of multiple cancers in the biliary tract is rare, with about 13 cases reported so far. The etiology most often held responsible is APBJ. In a review of 77 patients with $\mathrm{APBJ}^{1}$, the authors found that the cell proliferating activity of the biliary epithelium, as evaluated by PCNA-LI (proliferating cell nuclear antigen-labeling index), was significantly higher than that of the control group. The authors recommend routine prophylactic excision of the extrahepatic bile duct in APBJ patients. In our patient, there was simultaneous adenocarcinoma of the gallbladder and pancreas. Due to the large unresectable mass, it was difficult to ascertain the presence of APBJ, and, to identify normal intervening areas between the two cancers. However, the two cancers were different on histopathology, and CT scan showed a normal intervening common bile duct (CBD). Hence we can conclude that these were synchronous cancers.

A very striking aspect of multiple cancers in the biliary and GI tracts is the almost exclusive occurrence in Japanese patients. This is probably because biliary cancer and APBJ are both common in Japan, and, both genetic and physiological mechanisms are likely involved. ${ }^{8}$

NITIN AGARWAL SUNIL KUMAR ${ }^{1}$ SONAL SHARMA ${ }^{2}$

Correspondence: Dr. Nitin Agarwal Department of Surgery ${ }^{l}$ and Pathology ${ }^{2}$ University College of Medical Sciences and 


\section{Guru Teg Bahadur Hospital \\ Delhi, India \\ Email:_drnitinagarwal76@gmail.com}

\section{References}

1. Hara H, Morita S, Ishibashi T, Sako S, Dohi T, Otani M, Iwamoto $\mathrm{M}$, Inoue H, Tanigawa N. Studies on biliary tract carcinoma in the case with pancreaticobiliary maljunction. Hepatogastroenterology. 2002;49:104-8.

2. Nakao A, Sakagami K, Uda M, Mitsuoka S. Double cancers of the gallbladder and bile duct associated with anomalous choledochopancreatic duct junction. J Gastroenterol. 1997;32:110-3.

3. Itoh T, Fuji N, Taniguchi H, Yasukawa S, Yasuda H, Wakabayashi N, Watanabe T, Kosuga T, Kashimoto K, Yanagisawa A, Naito $\mathrm{K}$. Double cancer of the cystic duct and gallbladder associated with low junction of the cystic duct. $J$ Hepatobiliary Pancreat Surg. 2008;15:338-43.

4. Takayashiki T, Miyazaki M, Kato A, Ito H, Nakagawa K, Ambiru S, Shimizu H, Furuya S, Nakajima N. Double cancer of gallbladder and bile duct associated with anomalous junction of the pancreaticobiliary ductal system. Hepatogastroenterology. 2002;49:109-12.

5. Minami Y, Hasuike Y, Takeda Y, Tsujinaka T. Metachronous double cancer of the gallbladder and pancreas associated with pancreaticobiliary maljunction. J Hepatobiliary Pancreat Surg. 2008;15:330-3.

6. Sato K, Maekawa T, Yabuki K, Tamasaki Y, Maekawa H, Kudo K, Sengoku H, Kawa I, Wada R, Matsumoto M. A case of triple synchronous cancers occurring in the gallbladder, common bile duct, and pancreas. J Gastroenterol. 2003;38:97-100.

7. Ueda N, Nagakawa T, Ohta T, Kayahara M, Ueno K, Konishi I, Izumi R, Miyazaki I. Synchronous cancer of the biliary tract and pancreas associated with anomalous arrangement of the pancreaticobiliary ductal system. J Clin Gastroenterol. 1992;15:136-41.

8. Bartlett DL, Fong Y. Tumors of the gallbladder. In Blumgart LH, Fong Y (eds). Surgery of the liver and biliary tract. United Kingdom: Saunders; 2000:p993-1045.

\section{An unusual case of urinary ascites presenting as postoperative acute oliguric renal failure}

\section{Introduction}

Spontaneous urinary ascites is a rare clinical entity in adults. It is nearly always provoked by underlying bladder conditions; inflammatory, malignant, or obstructive. ${ }^{1,2}$ We report a case of spontaneous urinary ascites after upper abdominal surgery.

\section{Case Report}

A 36-year-old woman underwent open cholecystectomy for calculus cholecystitis. Pre-operative liver function tests, renal function tests, and complete blood counts were normal. Ultrasound abdomen showed multiple stones in the gallbladder (GB), with thickened GB and urinary bladder walls. Intraoperatively the liver was normal, the GB wall was thickened with multiple stones, and there was no free fluid in the abdomen. The other visceral organs were normal. The patient underwent cholecystectomy through right subcostal incision. On the $2^{\text {nd }}$ post-operative day, she developed abdominal distension, abdominal pain, fever, reduced urinary output, and tachycardia. On examination she was anxious, febrile and hemodynamically stable. Abdominal examination revealed abdominal distension with shifting dullness and diffuse tenderness. There was no pedal edema. A diagnosis of post cholecystectomy biliary peritonitis was made. Laboratory investigations showed hemoglobin $12.3 \mathrm{~g} / \mathrm{dL}$ (normal 12.1-15.1 g/dL); total leucocyte count 16,000 cells $/ \mathrm{m}^{3}\left(4800-10800\right.$ cells $\left./ \mathrm{m}^{3}\right)$. The urine examination showed $3+$ proteins, and 6-8 pus cells. Her serum creatinine, and urea nitrogen were $3.2 \mathrm{mg} / \mathrm{dL}$ (normal 0.6-1.4 $\mathrm{mg} / \mathrm{dL}$ ), and $56 \mathrm{mg} / \mathrm{dL}$ (normal 8-25 mg/dL) respectively, and liver function test was normal. Serum electrolyte test reported sodium $130 \mathrm{mEq} / \mathrm{L}$ (135-147mEq/L), potassium $5.9 \mathrm{mEq} / \mathrm{L}$ (3.5$4.8 \mathrm{mEq} / \mathrm{L})$, and chloride $96 \mathrm{mEq} / \mathrm{L}$ (98-108 mEq/L). The patient had no history of liver, or kidney disease, and her pre-operative serum creatinine level was normal. Plain x-ray abdomen and chest were within normal limits. On ultrasound examination, there was significant free fluid in the abdomen, both kidneys were normal, and the bladder showed a thickened wall. The patient was suspected for post cholecystectomy bile leak and the bladder was catheterized. Laparotomy was performed. Laparotomy findings were straw-colored fluid around $3 \mathrm{~L}$, not bile stained. Fluid was aspirated, and sent for analysis, culture and sensitivity. The abdomen was closed with a drain tube in situ. Biochemical analysis of the aspirated liquid revealed elevated urea $176 \mathrm{mg} / \mathrm{dL}$, creatinine $8 \mathrm{mg} / \mathrm{dL}$ and protein $5 \mathrm{~g} / \mathrm{L}$. Culture of the fluid was positive for Klebsiella pneumoniae. Sodium, potassium and chloride levels in the ascitic fluid were 32,17 and $71 \mathrm{mEq} / \mathrm{L}$, respectively, which differed markedly from the serum electrolyte level. The ascitic fluid-serum creatinine ratio was $>1.0$ (i.e. 8:3.2 mg/dL). A diagnosis of urinary ascites was made. She was treated with antibiotics to prevent bacterial translocation, as per fluid culture and sensitivity. After placement of the catheter, ascites subsequently resolved, and the serum creatinine level returned to normal. Urinary ascites 